\section{KEEP KIDS HAPPY}

Put your young patients at ease from the start. Admor has the latest reception furniture and products to make them feel especially welcome. The moving and fitting activity table is a colourful unit with shaped beads which glide easily around a frame.

The frame is easy to assemble and comes with no removable parts. Several children can use the table at the same time.

With its robust, multi-coloured appearance the animal furniture remains incredibly popular. It is available in designs including the frog, lion and teddy bear.

Make sure your practice provides maximum welcome to the youngest patients. Telephone 01243553078 for more information.
The e-touch range of dental education products enable you to educate, communicate and sell dental treatments to patients in the most appropriate way. Staff will know your treatment list inside out and will be able to answer any questions put to them. Patients can also find out as much as they like with all the information at their fingertips.

The e-touch system integrates simply into your waiting room - on the wall, in a kiosk or on the welcome desk. Users access the information via touch screen, and can discover a wealth of material. See

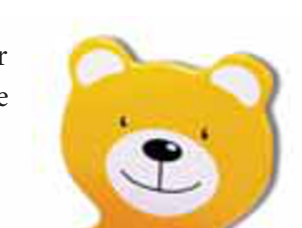

\section{TOUCH SCREEN} www.touch-ed.co.uk

\section{COMFORTABLE CONSULTATIONS}

If staff are seated comfortably at the right angle for whatever task they are carrying out, it will make a great difference to the atmosphere of the practice. Evident is so confident of this that they are offering a free two-week trial of their DynamoSeat and InCharge stools.

Ergonomically designed, they offer flexible seating positions, maximum support and all day comfort. Available in a range of colours they also offer value for money. Telephone 0500321111 for further information.
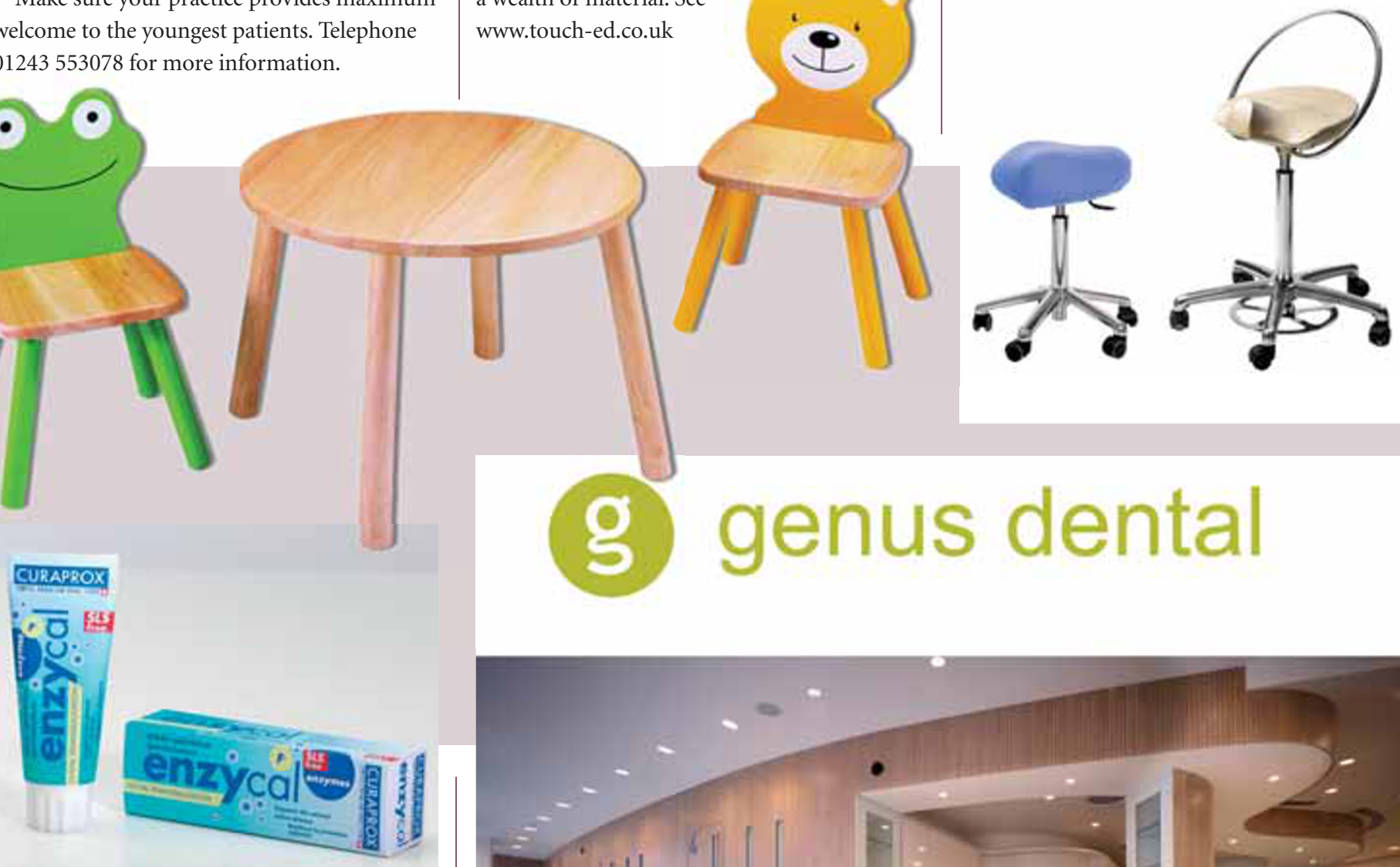

\section{PROMOTE ORAL HEALTH}

Make sure you include Cupraprox Enzycal in your practice to help patients achieve an effective oral and dental health regimen. Enzycal's remineralisation process is natural, its fluorides reintegrating mineral nutrients in the enamel, balancing or even reversing the lack of minerals in early dental caries.

It is free from Sodium Lauryl Sulphate (SLS) so does not nullify Chlorhexidine (CHX). It strengthens the body's own antibacterial saliva system and does not cause irritation. Patients using the toothpaste suffer fewer aphthous ulcers.

For more information ring 01480862080.

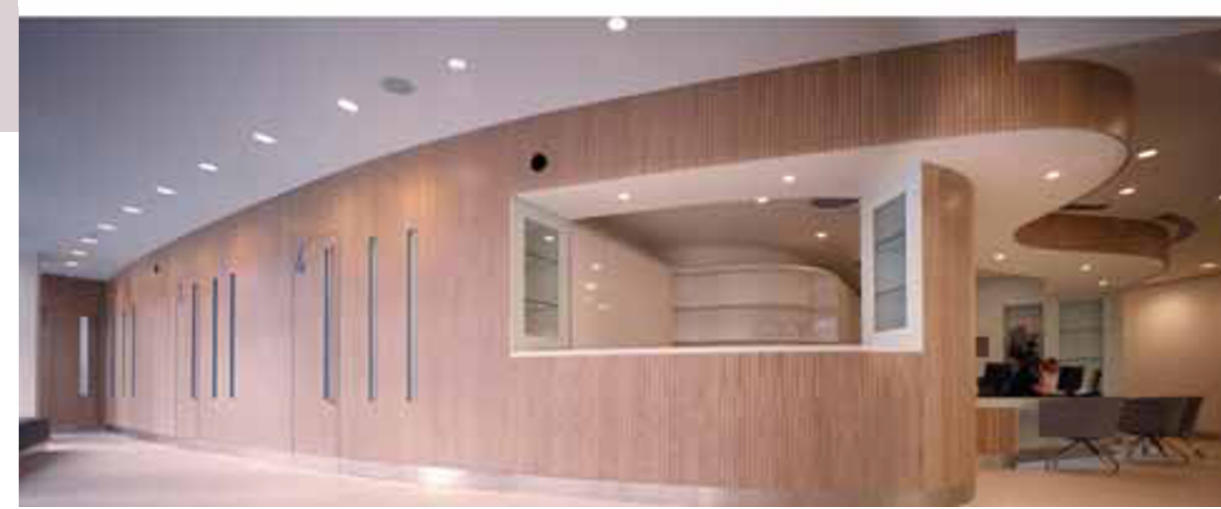

\section{NEW PRACTICE FOR THE NEW YEAR}

Considering renovating the practice, or starting a new one from scratch? Genus has been applying partnering concepts to its design, refurbishment and new build projects since 1992. Their approach ensures they will meet the high expectations of today's practitioners who need a stylish, well planned environment in order to achieve a competitive edge.
Projects will be completed on time and within budget and quality and total satisfaction are assured. Genus oversees every aspect of the project including the plumbing and flooring. All the client has to do is choose the equipment. And because it's not linked to any manufacturer Genus will also select the best furniture and equipment. Make sure you get the dream practice which matches your vision.

For further information telephone 01582840484. 